\title{
Tunable mW Narrow Bandwidth Mid-Infrared Light Source
}

Krenzen, Erik ; Kehlet, Louis M.; Tidemand-Lichtenberg, Peter; Dam, Jeppe Seidelin; Jensen, Ole Bjarlin; Pedersen, Christian

Published in:

Lasers, Sources, and Related Photonic Devices Technical Digest

Publication date:

2012

Document Version

Publisher's PDF, also known as Version of record

Link back to DTU Orbit

Citation (APA):

Krenzen, E., Kehlet, L. M., Tidemand-Lichtenberg, P., Dam, J. S., Jensen, O. B., \& Pedersen, C. (2012).

Tunable mW Narrow Bandwidth Mid-Infrared Light Source. In Lasers, Sources, and Related Photonic Devices Technical Digest (pp. AW4A.2). Optical Society of America.

\section{General rights}

Copyright and moral rights for the publications made accessible in the public portal are retained by the authors and/or other copyright owners and it is a condition of accessing publications that users recognise and abide by the legal requirements associated with these rights.

- Users may download and print one copy of any publication from the public portal for the purpose of private study or research.

- You may not further distribute the material or use it for any profit-making activity or commercial gain

- You may freely distribute the URL identifying the publication in the public portal

If you believe that this document breaches copyright please contact us providing details, and we will remove access to the work immediately and investigate your claim 


\title{
Tunable mW Narrow Bandwidth Mid-Infrared Light Source
}

\author{
Erik Krenzen, Louis M. Kehlet, Peter Tidemand-Lichtenberg, Jeppe S. Dam, \\ Ole B. Jensen and Christian Pedersen \\ DTU Fotonik, Department of Photonics Engineering Technical University of Denmark, DK-4000 Roskilde, Denmark \\ Corresponding author: ptli@fotonik.dtu.dk
}

\begin{abstract}
A Tunable Mid-IR light source base on single resonant Difference Frequency Generation (DFG) is experimentally investigated. The DFG process is pumped by an $800 \mathrm{~nm}$ tunable tapered diode laser. Grating feedback to the single mode channel of the tapered diode narrows the spectrum and allows for tuning of the diode laser wavelength by rotating the grating. The system tunes $500 \mathrm{~nm}$ using a single diode, ranging from $2.9 \mu \mathrm{m}$ to $3.4 \mu \mathrm{m}$ with mW's of output power over the entire range. The maximum measured output is $2.5 \mathrm{~mW}$ at $3.2 \mu \mathrm{m}$.
\end{abstract}

OCIS codes: (130.7405) Wavelength conversion devices; (140.3070) Infrared and far-infrared lasers; (140.5960) Semiconductor lasers;

\section{Introduction}

An increasing number of applications of lasers in the mid-IR spectral range have emerged in recent years. Particular for spectroscopy as many important gasses have their fundamental absorption lines, related to the $\mathrm{C}-\mathrm{H}$ bonds, in the 3-4 $\mu \mathrm{m}$ range $\left(2500-3000 \mathrm{~cm}^{-1}\right)$. A simple, narrow band, broadly tunable light source is therefore desirable for a range of spectroscopic applications.

Over the years different techniques has been applied to generate continuous waves output in the mid-IR spectral range. Recently quantum cascade lasers has shown to be very efficient for generation of IR radiation, however, they are still not efficient for wavelengths below $4 \mu \mathrm{m}$ [2].

Another way to reach the 3-4 $\mu \mathrm{m}$ wavelength range has been based on nonlinear frequency conversion. Periodically poled $\mathrm{LiNbO}_{3}$ (PP:LN) has proven to be a good nonlinear medium for generating tunable light in the mid-IR range [3-6]. One approach is to make use of a single resonant optical parametric oscillator (OPO) [3] which can be tuned widely, within the $3-5 \mu \mathrm{m}$ range [4]. However, such light sources need significant pump power from high quality lasers to compensate the threshold. Another approach has been single pass DFG using 2 fibre lasers [5]. Grating controlled tapered amplifiers mixed with a single-frequency Nd:YAG ring laser has been demonstrated to cover the $4.2 \mathrm{~nm}$ to $4.6 \mathrm{~nm}$ range rotating the PP:LN crystal for angle tuning [6].

We present efficient singly-resonant DFG by single pass of an external cavity tunable tapered diode laser and the resonant field of a high finesse $1064 \mathrm{~nm}$ diode pumped solid-state laser. Tapered diodes has a broad tuning range (10's of $\mathrm{nm}$ ) in the near infrared region [7], which makes them the ideal pump sources for a broadly tunable Mid-IR light source. In the DFG process the wavelength tuning range of the tapered diode is scaled corresponding to the shift in centre wavelength, when converted to the mid-IR range. Any wavelength changes correspond to a phase mismatch due to dispersion. This is compensated by a change of the PP:LN crystal temperature of shifting to a differently poled region of the crystal. The setup allow for higher conversions as the solid state lasers have a high intra cavity power, this technique has also been demonstrated in sum frequency generation [8]. However, in sum frequency generation the tuning is limited by the fact that a change in fundamental wavelength will give rise to a smaller change in generated wavelength. A fully computerized system has been made, controlling the wavelength of the tapered diode laser by motorized actuators rotating the external grating, using a spectrum analyzer for wavelength feedback, and controlling the temperature of the PP:LN crystal to optimize conversion efficiency. All parameters was controlled by a LabVIEW program, including the pump currents for the tapered diode laser and pump diode for the solid-state laser and using a power meter for feedback of the generated mid-IR power. This turnkey system allows the user to set the desired mid-IR wavelength and power where after the program optimize all parameters.

\section{Experimental setup}

The intra cavity DFG experiment is shown in Fig. 1. The Nd: $\mathrm{YVO}_{4}$ solid-state laser is pumped by a $4 \mathrm{~W} 808 \mathrm{~nm}$ broad area laser diode. The laser crystal is $8 \mathrm{~mm}$ long, $0.5 \mathrm{~atm} \%$. Nd-doped Nd:YVO${ }_{4}$ with one facet HR@1064 nm and AR@808 nm and the other AR coated. The high finesse V-shaped cavity comprises two additional mirrors, a concave mirror HR@1064 nm and BBAR@800 nm with a radius of curvature of 100 mm, and a concave mirror 
HR@1064 nm and BBAR@3-4 mm with a radius of curvature of $50 \mathrm{~mm}$, acting as the mid-IR output coupler. The distance between the $\mathrm{Nd}: \mathrm{YVO}_{4}$ and the $100 \mathrm{~mm}$ mirror is $155 \mathrm{~mm}$, and the separation of the two concave mirrors are $110 \mathrm{~mm}$. The configuration results in a beam waist of approx. $200 \mu \mathrm{m}$ in the laser crystal, and a smaller beam waist of $60 \mu \mathrm{m}$ located $50 \mathrm{~mm}$ from the output mirror. A $10 \mathrm{~mm}$ long PP:LN crystal is inserted at the smaller beam waist. It has 5 differently poled channels allowing for difference frequency generation in the region 2.9-5 $\mu \mathrm{m}$.

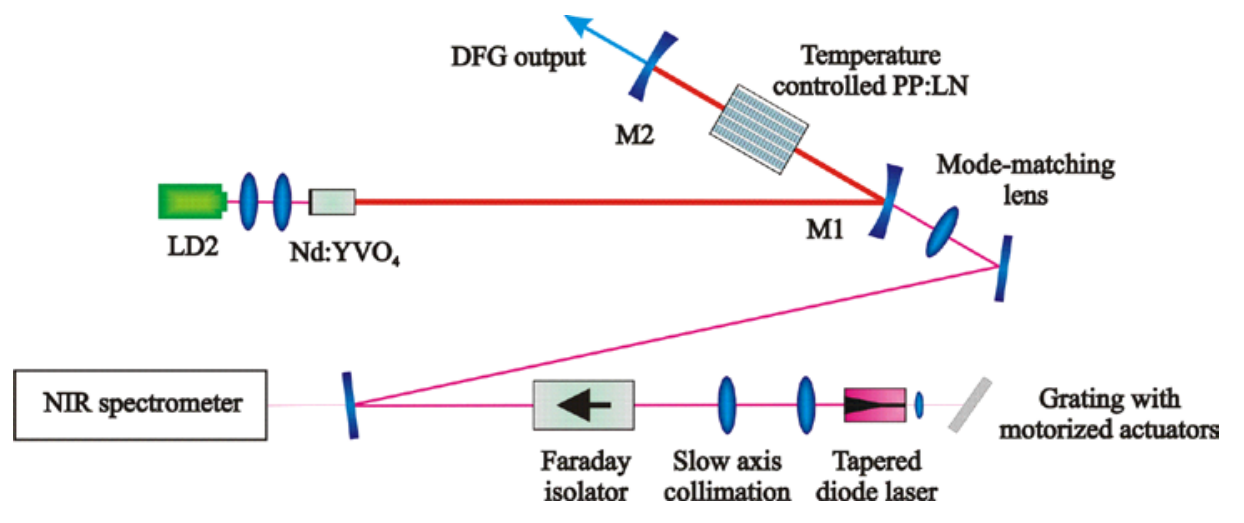

Fig. 1. Cavity layout consisting of a tunable external cavity tapered diode laser, and difference frequency in a PP:LN crystal, situated in the cavity of a solid-state Nd-doped laser.

The tapered amplifier is AR coated on both facets where the emission through the single mode channel is collimated and retransmitted into the single mode channel by grating feedback. The grating is used for spectral narrowing of the output coming out of the tapered end of the device. By rotating the grating the center wavelength changes in steps corresponding to the separation of longitudinal modes. The output is collimated by a spherical lens in the fast axis and in the slow axis using an additional cylindrical lens and passed through an optical isolator. The transmitted light is aligned and mode-matched to the cavity mode in the PP:LN crystal by two plane mirrors and a $100 \mathrm{~mm}$ lens. This forms a beam waist for the tapered diode laser of approx. $50 \mu \mathrm{m}$ in the PP:LN crystal.

\section{Results and discussion}

Measurements of the external cavity diode laser shows a linear relationship between the pump current and the generated NIR power, two examples shown at $800 \mathrm{~nm}$ in fig. 2 (a). The spectrum is tuned by motorized actuators on the feedback grating, resulting in $>30 \mathrm{~nm}$ tuning range, white a very narrow spectrum at all settings, as seen in fig. 2 (b). The diode emits light with a bandwidth of $<50 \mathrm{pm}$ and an $\mathrm{M}^{2}$ of approx. 1.2 and 2 for the fast and slow axis of the diode, respectively.
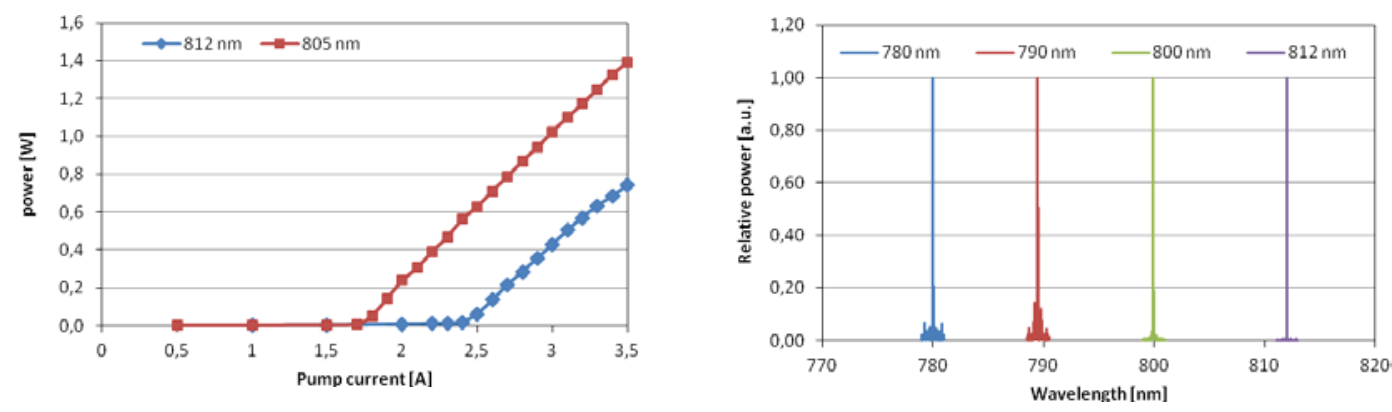

Fig. 2. (a) Measured slope efficiency of the tapered diode laser when operated at $800 \mathrm{~nm}$. (b) Examples of the measured spectrum from the tapered diode laser.

Difference frequency mixing of two light sources makes use of a linear relation between the power of the singlepass fundamental waves and the generated light beam. The relation is given as

$$
P_{3}=\eta_{D F G} P_{1} P_{2}
$$

The conversion from tapered diode laser output to the mid-IR spectral range is shown in Fig. 2. As seen from fig. 3 (b) the tuning range of the tapered diode laser result in approx. $500 \mathrm{~nm}$ tuning in the mid-IR range. The generated wavelength can be calculated using according to (2). 


$$
\frac{1}{\lambda}_{I R}=\frac{1}{\lambda_{L D}}-\frac{1}{\lambda}
$$

Where $\lambda_{\mathrm{IR}}, \lambda_{\mathrm{LD}}$, and $\lambda_{\mathrm{SS}}$ are the wavelength of the mid-IR, laser diode and solid-state laser, respectively.
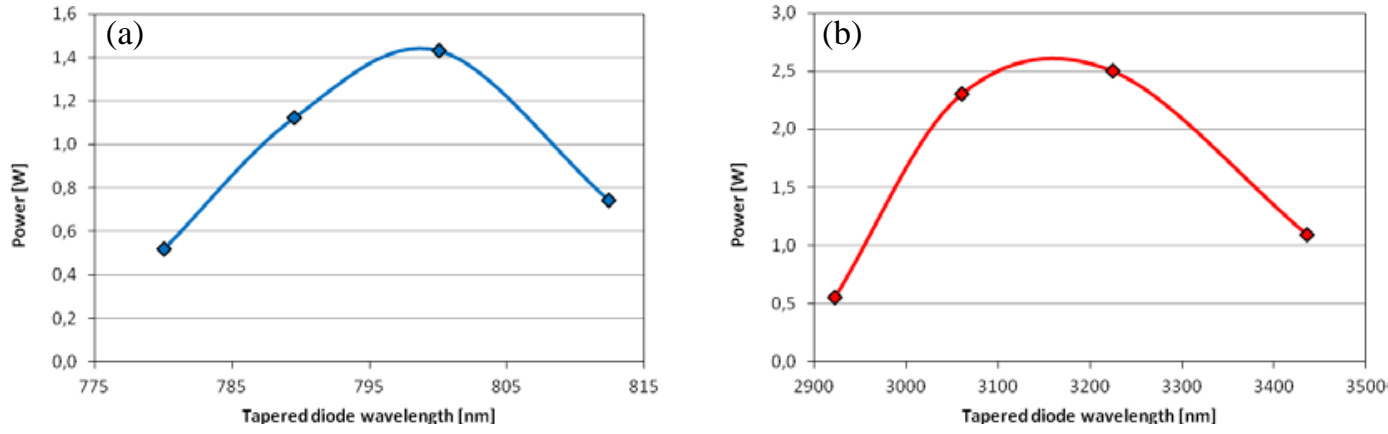

Fig. 3. Measured power (a) from the external cavity tapered diode laser and (b) the generated mid-IR power.

The phase-matching condition has to be optimized while tuning the diode laser. This is done by control of the temperature of the PP:LN crystal. Knowing the wavelength of the two fundamental fields, the calculation of the appropriate phase-match temperature, for a given poling period is straight forward. The PP:LN crystal has 5 channels with different poling periods. For each channel the temperature can be controlled between $60{ }^{\circ} \mathrm{C}$ and $200^{\circ} \mathrm{C}$. When the phase-matching temperature exceeds $200^{\circ} \mathrm{C}$ the crystal is moved to the next channel with longer periods.

The bandwidth of the generated light beam is a convolution of the spectrum of the narrow bandwidth tapered diode and the free running solid state laser. In the present system the solid-state laser is setup as a standing wave cavity, which means that it oscillates on several longitudinal modes, however, the system is easily converted to a singly-frequency system, as a result the generated spectrum of the mid-IR power becomes very narrow.

\section{Conclusions and outlook}

We demonstrate $500 \mathrm{~nm}$ tuning of an intra cavity DFG from $2.9 \mu \mathrm{m}$ to $3.4 \mu \mathrm{m}$ using a single tapered diode. The setup is fully computer controlled; inserting the desired wavelength, a LabVIEW program adjusts all parameters to reach the selected wavelength. The setup consists of two modules, the solid-state laser part and the single-pass tapered diode laser; using two tapered diodes, spectrally offset relative to each other, the spectral coverage of the system can be extended further.

\section{References}

[1] T. Töpfer, K. P. Petrov, Y. Mine, D. Jundt, R. F. Curl, and Frank K. Tittel, Appl. Opt. 36, 8042-8049 (1997)

[2] S.Y. Zhang, D.G. Revin, J.W. Cockburn, K.Kennedy, A.B. Krysa and M. Hopkinson, Appl. Phys. Lett. 90, 031106 (2009).

[3] P. Gross, M. E. Klein, T. Walde, K.-J. Boller, M. Auerbach, P. Wessels, and C. Fallnich, Opt. Lett. 27, 418-420 (2002)

[4] L. E. Myers, R. C. Eckardt, M. M. Fejer, R. L. Byer, and W. R. Bosenberg, Opt. Lett. 21, 591-593 (1996)

[5] J. Chang, Q. Mao, S. Feng, X. Gao, and C. Xu, Opt. Lett. 35, 3486-3488 (2010)

[6] L. Goldberg, W. K. Burns, and R. W. McElhanon, Appl. Phys. Lett. 67, 2910 (1995).

[7] M. Chi, O. B. Jensen, J. Holm, C. Pedersen, P. E. Andersen, G. Erbert, B. Sumpf, and P. M. Petersen, Opt. Express 13, 10589-10596 (2005)

[8] E. Karamehmedovic, C. Pedersen, M. T. Andersen, and P. Tidemand-Lichtenberg, Opt. Express 15, 12240-12245 (2007) 